\title{
Engineering Biomaterials and Approaches for Mechanical Stretching of Cells in Three Dimensions
}

\author{
Weiwei Zhang ${ }^{1}$, Guoyou Huang ${ }^{2,3 *}$ and Feng $\mathrm{Xu}^{4,5}$ \\ ${ }^{1}$ Faculty of Materials Science and Chemistry, China University of Geosciences, Wuhan, China, ${ }^{2}$ Key Laboratory \\ of Biorheological Science and Technology (Chongqing University), Ministry of Education, Chongqing University, Chongqing, \\ China, ${ }^{3}$ Department of Engineering Mechanics, School of Civil Engineering, Wuhan University, Wuhan, China, ${ }^{4}$ Bioinspired \\ Engineering and Biomechanics Center, Xi'an Jiaotong University, Xi'an, China, ${ }^{5}$ The Key Laboratory of Biomedical \\ Information Engineering of Ministry of Education, School of Life Sciences and Technology, Xi'an Jiaotong University, Xi'an, \\ China
}

OPEN ACCESS

Edited by:

Qiang Wei,

Sichuan University, China

Reviewed by: Jin' Qian,

Zhejiang University, China Wenqian Feng,

Max Planck Institute for Medical Research, Germany

*Correspondence:

Guoyou Huang

gyhuang@whu.edu.cn

\section{Specialty section:}

This article was submitted to

Biomaterials,

a section of the journal Frontiers in Bioengineering and

Biotechnology

Received: 31 July 2020 Accepted: 09 September 2020

Published: 14 October 2020

Citation:

Zhang W, Huang G and Xu F (2020) Engineering Biomaterials and Approaches for Mechanical

Stretching of Cells in Three

Dimensions.

Front. Bioeng. Biotechnol. 8:589590. doi: 10.3389/fbioe.2020.589590
Mechanical stretch is widely experienced by cells of different tissues in the human body and plays critical roles in regulating their behaviors. Numerous studies have been devoted to investigating the responses of cells to mechanical stretch, providing us with fruitful findings. However, these findings have been mostly observed from twodimensional studies and increasing evidence suggests that cells in three dimensions may behave more closely to their in vivo behaviors. While significant efforts and progresses have been made in the engineering of biomaterials and approaches for mechanical stretching of cells in three dimensions, much work remains to be done. Here, we briefly review the state-of-the-art researches in this area, with focus on discussing biomaterial considerations and stretching approaches. We envision that with the development of advanced biomaterials, actuators and microengineering technologies, more versatile and predictive three-dimensional cell stretching models would be available soon for extensive applications in such fields as mechanobiology, tissue engineering, and drug screening.

Keywords: mechanobiology, stretch, tissue engineering, hydrogels, cell mechanotransduction

\section{INTRODUCTION}

Cells in the human body experience various mechanical forces such as tensile, shear, compressive, torsional and hydrostatic forces, with mechanical features depending on specific tissue types, development stages and body conditions (Polacheck et al., 2013; Giulitti et al., 2016; Huang G. et al., 2019). Specially, cells in the lung and heart are cyclically subjected to mechanical stretch during breathing and heart beating (Figure 1). Such stretching force plays important roles in regulating the behaviors of lung and heart cells, and thus the development and performances of the lung and heart (Sheehy et al., 2012; Liu Z. et al., 2016; Stoppel et al., 2016; Watson et al., 2019). Mechanical stretch can be also commonly found in many other tissues or organs such as skeletal and smooth muscles, tendon, vessel, intestine, bladder and cartilage, etc., prominently regulating the behaviors of cells in these systems (Qi et al., 2016; Landau et al., 2018; Rinoldi et al., 2019). For instance, mechanical stretch has been widely demonstrated to promote the maturation and growth of muscles 


\section{A Pulmonary respiration}

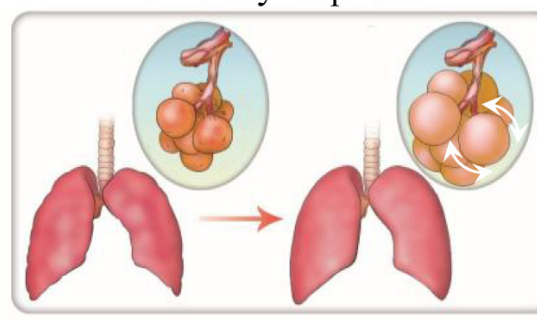

c Vessel blood flow

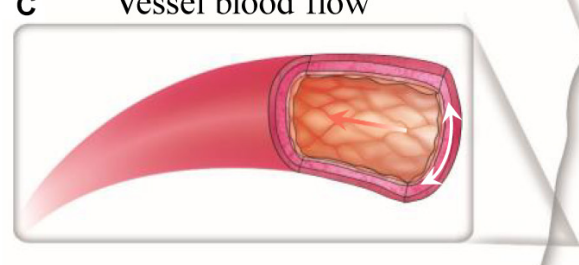

E Intestinal movement

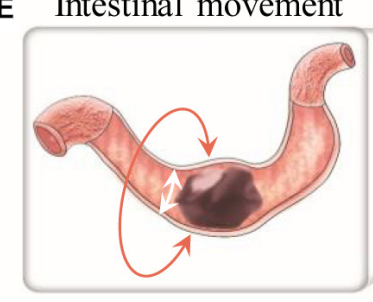

B

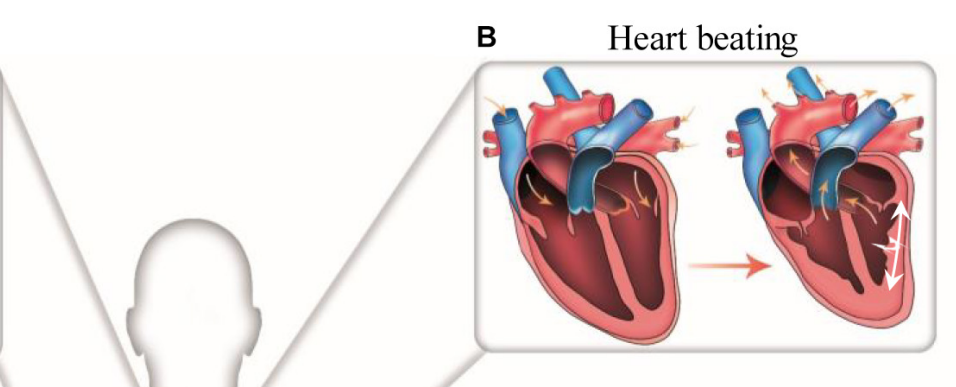

D Skeletal muscle contraction
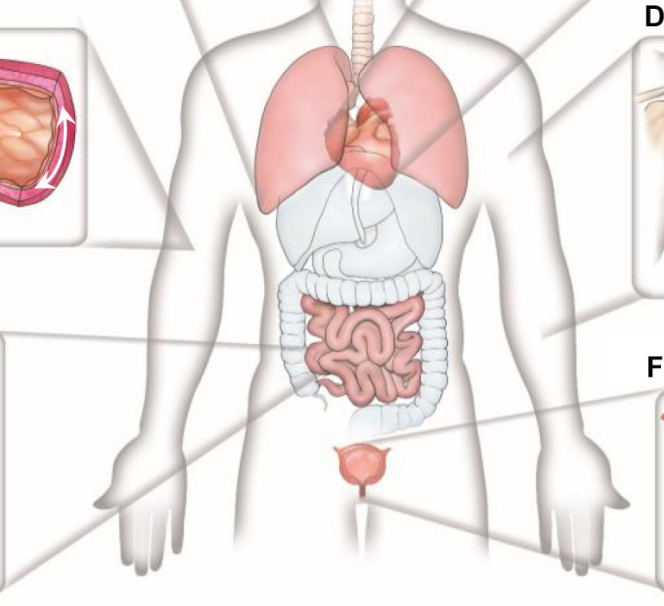

F

Bladder urination

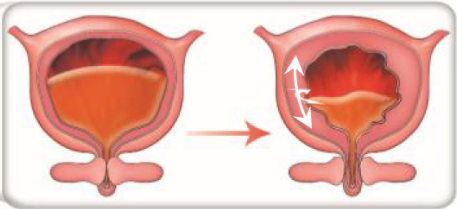

FIGURE 1 | Mechanical stretch in the human body. Representative stretching forces in different human tissues and organs are indicated by white arrows. (A) Cells in the alveoli undergo cyclic dilatational stretching during pulmonary respiration. (B) Cells in the myocardium experience cyclic circumferential and longitudinal stretching during heart beating. (C) Cells in the vessel wall are continuously subjected to circumferential stretching due to the action of blood pressure. (D) Cells in the skeletal muscle experience uniaxial stretching when moving the body. (E) Cells in the intestinal wall undergo circumferential stretching during intestinal peristalsis. (F) Cells in the bladder wall experience circumferential and longitudinal stretching at the time of urination.

(Li et al., 2015; Weinberger et al., 2017). Intestinal stretch as induced by food-intake was recently found to be able to stimulate cells in the intestinal wall to generate satiety signals for feeding regulation (Bai et al., 2019).

Mechanical stretch can be originally generated from external loading or internal active contraction, and may specifically elicit cell responses different from that induced by other mechanical stimuli (Maul et al., 2011; Zhong Z. et al., 2011). Almost all aspects of cell behaviors, including cell shape, orientation, proliferation, secretion, gene and protein expression, lineage differentiation and apoptosis, have been found to be regulated by mechanical stretching, with actual effects depending on cell types, stretch parameters, and culture conditions (Li Y. et al., 2014; Xu et al., 2016; Chen et al., 2018; He et al., 2018). By responding and adapting to mechanical stretching, cells can maintain their mechanical integrity and modulate their tensional state to sustain mechanical equilibrium, i.e., tensional homeostasis (Brown et al., 1998; Humphrey et al., 2014; Cheng et al., 2017). The disruption of tensional homeostasis usually leads to mechanical force-associated diseases, including defective morphogenesis or pathological dysfunctions such as fibrosis and cancer (Cambré et al., 2018; Bonnevie et al., 2019; Boudou et al., 2019). For example, chronically elevated cyclic stretch can induce abnormal proliferation and migration of vascular smooth muscle cells to mediate pathological vascular remodeling during hypertension (Qi et al., 2010). As a recent excellent example, Sainz de Aja and Kim (2020) and Wu et al. (2020) found that in idiopathic pulmonary fibrosis (IPF, the most common type of lung fibrosis), loss of Cdc42 function in alveolar stem cells (AT2 cells) results in impaired alveolar regeneration and consequently exposes AT2 cells to sustained elevated mechanical tension. Such aberrant elevated and likely spatial-specifically distributed mechanical tension generates an activation loop of TGF- $ß$ signaling in AT2 cells in a spatially regulated manner, driving periphery-to-center progression of IPF.

Various biomaterials and approaches have been developed for mechanical stretching of cells, most of which have been performed on two-dimensional (2D) substrates (Kurpinski et al., 2006; Yung et al., 2009; Cui et al., 2015; Wang et al., 2015; Kamble et al., 2016). In such studies, monolayer of cells is usually cultured on the surface of elastic membranes made of elastomer [typically polydimethylsiloxane (PDMS)] or hydrogels. By inducing expanding or bending deformation of the elastic membranes, mechanical stretch can be generated and applied to the cells cultured on them (Huh et al., 2010; Faust et al., 2011; Mann et al., 2012; Jiang et al., 2018). Various approaches, commonly including motor-driven, indentation, 


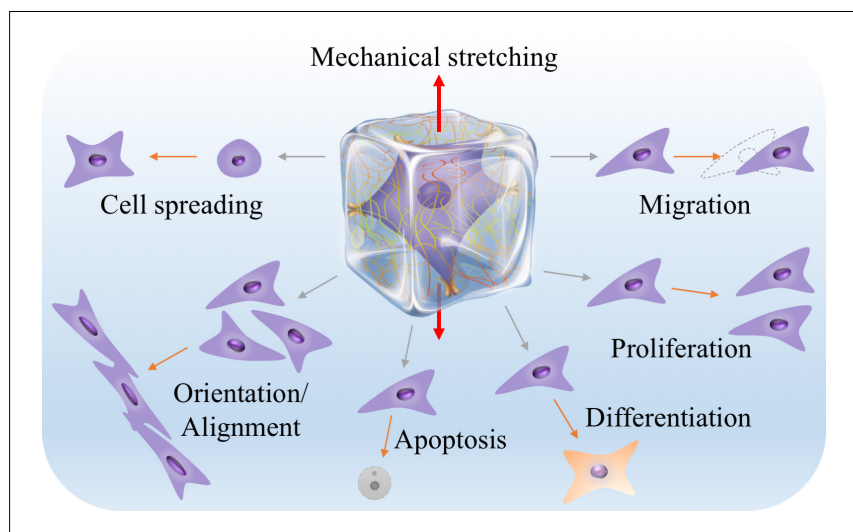

FIGURE 2 | Many aspects of cell behaviors, including cell spreading, migration, orientation or alignment, proliferation, apoptosis and lineage differentiation, can be influenced by 3D mechanical stretching. The middle illustration was reprinted with permission from (Huang et al., 2017).

pneumatic actuation, magnetic and electromagnetic actuation, have been developed to induce mechanical deformation of the elastic membranes. Thanks to the simple configuration and easy manipulation of elastic membranes, the responses of cells to mechanical stretch of diverse parameters varying in stretch mode (uniaxial, biaxial, and equiaxial), stretch waveform (static, sinusoidal, and ramp), insertion of rest periods, strain magnitude, rate or frequency, have been systematically investigated (Balestrini and Billiar, 2009; Zhong Y. et al., 2011; Zhao G. et al., 2019). In addition, specific dielectric (Poulin et al., 2016, 2018; Imboden et al., 2019) and electrochemical (Svennersten et al., 2011; Guan et al., 2018) actuators have been developed to achieve ultra-fast dynamic cell stretching or high-throughput single cell stretching, respectively. Moreover, local stretch of subcellular or even molecular structures has been reported by employing specially designed magnetic tweezers (Tajik et al., 2016; Sun et al., 2020), optical tweezers (Han et al., 2018, 2020) or other micromanipulators (Kim et al., 2009; Scheiwe et al., 2015). These studies have dramatically benefited the understanding of mechanical stretch-associated mechanobiology and cell mechanotransduction.

Nevertheless, increasing evidence shows that the dimensionality of the microenvironment where cells reside in may greatly influence the responses of cells to mechanical stimuli including stretch stimulation (Riehl et al., 2012; Caliari et al., 2016). Since majority of cells in the human body are embedded in complex three-dimensional (3D) extracellular matrix (ECM), it is reasonable to expect that, as have been already widely demonstrated, studying cell behaviors in a $3 \mathrm{D}$ engineered microenvironment can better recapture native cell responses than in two dimensions. Similar to but could be different from the findings from $2 \mathrm{D}$ studies, stretch forces in 3D have been found to influence many aspects of cell behaviors, including cell spreading, migration, orientation or alignment, proliferation, apoptosis and lineage differentiation (Figure 2). Therefore, engineering biomaterials and approaches for mechanical stretching of cells in three dimensions have attracted increasing interests, particularly in the engineering of $3 \mathrm{D}$ tissue constructs for applications in basic research, tissue engineering, regenerative medicine and drug screening (Zimmermann et al., 2006; Eyckmans and Chen, 2017; Huang et al., 2017). To allow $3 \mathrm{D}$ cell culture, cells are usually encapsulated in hydrogels or 3D scaffolds. Stretch forces are thus transmitted to the encapsulated cells through deformed meshes of hydrogels. Unlike stretching of cells on 2D elastic membranes, stretching of cells in 3D hydrogels may encounter some practical issues such as difficult to anchor and stretch hydrogels, limitation in controlling stretch parameters, insufficient supply of nutrients and oxygen, and challenges in $3 \mathrm{D}$ mechanical and biological characterizations (Riehl et al., 2012). Despite all these, significant efforts and progresses have been made to mechanically stretch cells and study their responses in a $3 \mathrm{D}$ engineered microenvironment over the past decade.

In this article, we briefly review the state-of-the-art advances in the engineering of biomaterials and approaches for mechanical stretching of cells in three dimensions. We first discuss biomaterial considerations for mechanical stretching of cells in three dimensions from mechanical, structural and biochemical aspects, respectively. We then summarize research status of hydrogel anchoring and actuation approaches for mechanical stretching of cells in three dimensions. Finally, concluding remarks and perspectives are given.

\section{ENGINEERING BIOMATERIALS FOR MECHANICAL STRETCHING OF CELLS IN THREE DIMENSIONS}

Most of the cells in vivo, if not all, inherently adhere to the ECM or cells for survival and growth. The ECM provides not only structural support but also various mechanical and biochemical cues for directing cell behaviors. This has recently been comprehensively reviewed in the literature (Huang et al., 2017). To mimic the ECM, hydrogels have been widely used in 3D cell culture. From the aspects of mechanical stretching, hydrogels can not only transmit stretch forces to the resident cells, forcing cells to stretch, but also respond to mechanical stretch itself via structural remodeling and biochemical molecule regulation, all of which can have profound effects on cell behaviors (Vader et al., 2009; Gaul et al., 2018; Liu et al., 2020; Pei et al., 2020). It is therefore reasonable to include mechanical, structural and biochemical considerations when engineering hydrogels for mechanical stretching of cells in three dimensions (Figure 3; Li et al., 2017; Davidson et al., 2020).

\section{Mechanical Considerations}

Mechanical properties of the hydrogels used in 3D cell culture determine the stress (the force over a given area) or strain (a description of deformation in terms of relative displacement of particles in the body) that can be generated in hydrogels under defined loading forces. The most studied and the primary considered mechanical property of the hydrogels is stiffness the extent to which an object resists deformation in response 


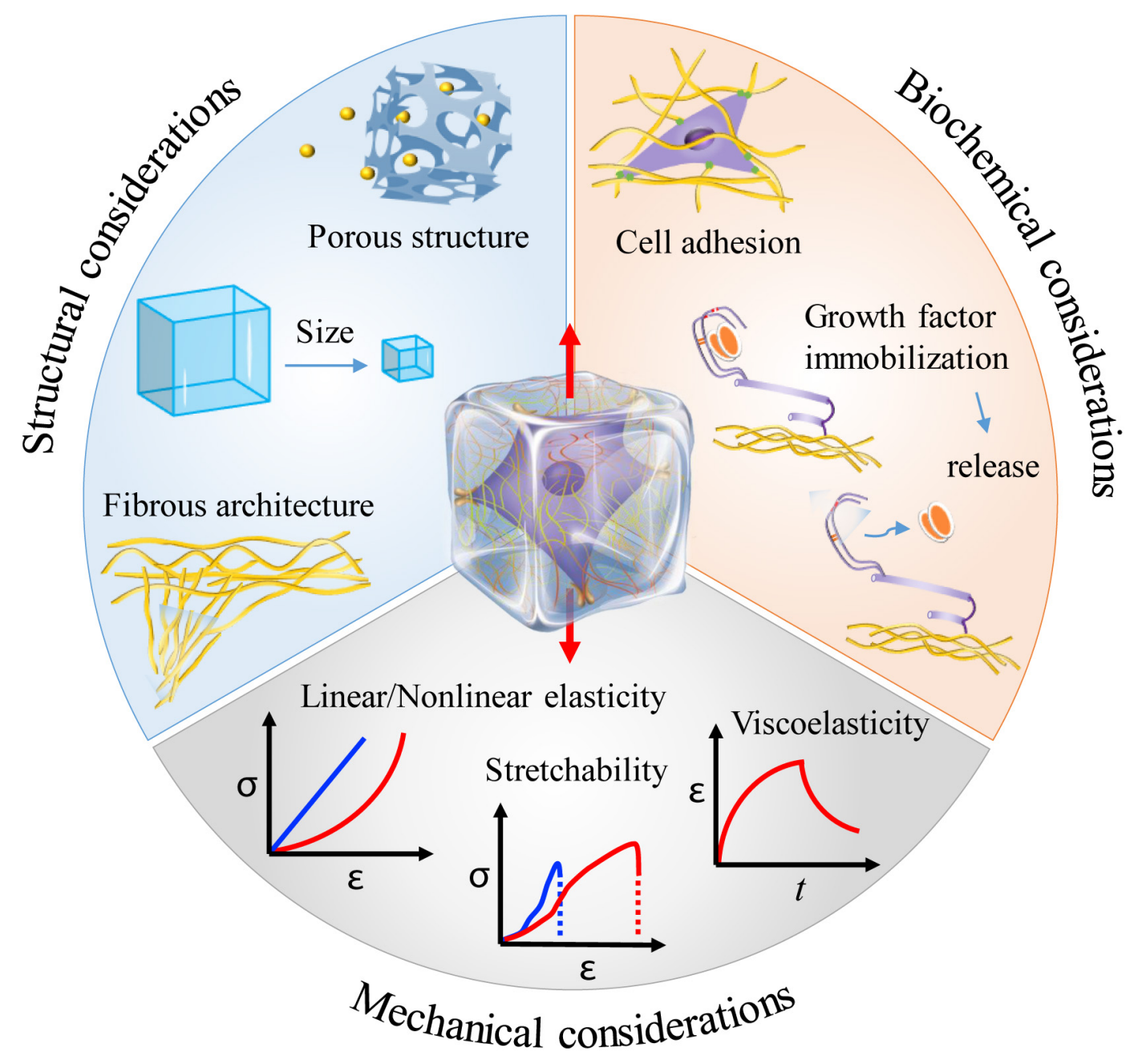

FIGURE 3 | Material considerations when engineering hydrogels for mechanical stretching of cells in three dimensions. Hydrogels can provide diverse mechanical, structural and biochemical cues that may greatly affect cell responses to mechanical stretching in three dimensions. The middle illustration was reprinted with permission from Huang et al. (2017).

to an applied force (Engler et al., 2006; Li et al., 2017; Wang M. et al., 2019). In practice, stiffness is usually characterized by elastic modulus or Young's modulus (the slope of the stressstrain curve in the linear elastic region). High stiffness may shield cells from high strain by resisting deformation. However, it should be noted that stiffness itself is widely found to play critical roles in regulating cell behaviors. For example, as the most widely distributed cells in the human body, fibroblasts orchestrate ECM homeostasis by responding to diverse microenvironment cues including matrix stiffness (van Putten et al., 2015). In the heart, pathological development of cardiac fibrosis typically leads to increased matrix stiffness and thus reduced local mechanical strains under heart beating, which cooperatively regulate fibroblast activation and fibrosis development (Yong et al., 2015). Interestingly, a recent work reported that cell mechanosensing is not only regulated by substrate stiffness, but also by strain energy (Panzetta et al., 2019). This further complicates the interpretation of cell mechanosensing and the design of biomaterials for engineering the cell mechanical microenvironment, since straining biomaterials usually leads to corresponding changes in matrix stiffness, showing a nonlinear strain-stress relationship as will be discussed below. In this case, it will be difficult to decouple the effects of strain from stiffness. Fortunately, advanced hydrogels with a linear strain-stress relationship in a wide strain range are available (Li et al., 2016a,b).

When applied for mechanically stretching cells in three dimensions, the stretchability of hydrogels should be taken into account, especially when large strains are expected such as for investigating tendons and muscles. Possibly the simplest ways of enhancing hydrogel stretchability are by reducing polymer concentration or by increasing characteristic network length. However, they are usually accompanied by a significant decrease of hydrogel stiffness, which is not expected in most cases. Therefore, certain efforts that can be generally classified into material composition- and structure-based approaches have been 
made to develop highly stretchable and/or tough (the ability to resist fracture by absorbing and dissipating mechanical energy) hydrogels (Li J. et al., 2014; Feng et al., 2016). In the material composition-based approach, components with complementary properties are combined to form hybrid hydrogels, in which one component endows the hydrogels high stretchability and the other component mainly works to absorb or dissipate mechanical energy (Sun et al., 2012). While the fabrication of such hybrid hydrogels often require toxic chemicals and/or harsh processing conditions, recent studies did report some biocompatible hybrid hydrogels [e.g., poly(ethylene glycol)/sodium alginate hydrogels (Hong et al., 2015)] that can be used for cell encapsulation and long-term 3D cell culture, maintaining high stretchability and toughness. In the structure-based approach, hydrogels are fabricated into special structural forms that can bear large deformations. For example, when fabricated into microscales, hydrogels of gelatin methacrylate (GelMA) can be stretched up to three times of its initial length (Li et al., 2016b). Further improvement can be achieved by fabricating hydrogels into hierarchical helical structures (Li et al., 2019).

As mentioned above, one of the important mechanical features of many native ECM and natural biomaterials (e.g., type I collagen and fibrin) is the non-linear stress-strain relationship, mostly exhibiting strain-stiffening behavior (i.e., the stiffness is not constant but increases with increasing strain) when subjected to large deformations (Storm et al., 2005; Licup et al., 2015). As for type I collagen and fibrin, the non-linear strainstiffening behavior was found to be dependent on strain history (Münster et al., 2013). The fibrous nature of these ECM proteins, including recruitment and alignment, is central to their effects. Moreover, the integration of other material components (e.g., polysaccharide matrix) with these fibrous proteins may have profound effects on their non-linear strain-stiffening behavior (Burla et al., 2019). Cells can actively use stiffening to strain their microenvironment and generate positive mechanical feedback from the ECM to modulate their functions (Jaspers et al., 2014; Das et al., 2016; Hall et al., 2016; Han et al., 2018). From mechanical stretching aspects, hydrogels with non-linear strain-stiffening property enables long-range transmission of mechanical forces and thus long-range cell-cell communications (Wang H. et al., 2014; Sopher et al., 2018). Moreover, such property is believed to be important in preventing overlarge tissue deformation, maintaining tissue integrity and thus shielding cells from overstretching (Wen and Janmey, 2013). Nevertheless, cells of diverse types, including fibroblasts and epithelial cells, may still subject to severe deformations even at physiological conditions as they engage in migration, invasion and lumen dilation (Trepat et al., 2007). Interestingly, these cells are not just passively receiving mechanical forces from external loading. They can respond to mechanical forces by dynamically adapting their cytoskeleton networks to withstand substantial deformations (Fletcher and Mullins, 2010). For instance, actin filaments and microtubules can yield and disassemble under moderate strains, while vimentin containing intermediate filaments forms a stretchable, hyperelastic network that can maintain cell viability at large deformations and increase the stretchability, strength and toughness of the cytoplasm (Hu et al., 2019). Therefore, epithelial cells can undergo extreme stretching and enter a state of non-linear superelasticity (the deformation increases without a corresponding increase in tension) (Latorre et al., 2018).

Many hydrogels exhibit not only solid- (elastic) but also fluid-like (viscous) characteristics when undergoing deformation (Pryse et al., 2003; Babaei et al., 2016; Nam et al., 2016a). The viscosity of a hydrogel may arise from weak bond dissolution, molecular slipping, polymer disentanglement or protein unfolding, etc. Such viscoelastic property endows hydrogels the ability to dissipate energy, allowing stress relaxation (a time-dependent decrease in stress under a constant strain) or creep (a time-dependent increase in deformation under a constant stress). Under dynamic loading conditions, the viscoelasticity of hydrogels can be significantly depending on strain rate. Remarkable efforts and progress have been made in recent years toward the development of advanced viscoelastic hydrogels, with certain results showing that the hydrogel viscoelasticity may greatly influence cell morphology, proliferation and differentiation (Chaudhuri et al., 2015, 2016; Bauer et al., 2017; Charrier et al., 2018; Gong et al., 2018; Lou et al., 2018; Huang D. et al., 2019; Cantini et al., 2020). In addition to viscoelasticity, some hydrogels (especially reconstituted fibrous hydrogels such as type I collagen) may undergo plastic deformation (a non-reversible permanent change in shape) when subjected to mechanical loadings (Kim et al., 2017; Ban et al., 2018; Ming et al., 2020). Such property can be explored by contractile cells to remodel the ECM, inducing local persistent alignment and densification of ECM fibers for facilitating cell migration and fibrosis development (Nam et al., 2016b; Wisdom et al., 2018).

\section{Structural Considerations}

In $3 \mathrm{D}$ cell culture, a great challenge is to maintain high cell viability. Bulk hydrogels used for encapsulating cells usually have a diffusion limit of several hundred micrometers, beyond which the cells may suffer from significant exhaustion of oxygen and nutrients (Huang et al., 2011). Dynamic mechanical stretching has been found to be able to facilitate oxygen and nutrient transport in hydrogels, however, usually it could not be sufficient to guarantee cell survival (Vaughan et al., 2013). Therefore, it is necessary to introduce additional macroscale porous or even microfluidic structures into bulk hydrogels to enable convective mass transport (Choi et al., 2007; Huang et al., 2013). However, attention should be paid to avoid structural collapses, maintaining hydrogel mechanical stability under both perfusion culture and mechanical stretching (Huang et al., 2012). Perhaps the most effective way to overcome diffusion limitation is to reduce the size of cell-laden hydrogels. As a result, various microengineering technologies have been developed to fabricate microscale engineered tissues (i.e., microtissues), which not only overcome diffusion limitation, but also bring benefits such as the save of materials and cells, high throughput, as well as enhanced mechanical stretchability as already mentioned in section "Mechanical Considerations" (Wang L. et al., 2014; Guven et al., 2015; Zhu et al., 2017). In practice, it may cause more difficulties in mechanically stretching microtissues. Nevertheless, with the development of 
advanced microfabrication and actuation technologies, various approaches have been explored for simultaneously stretching multiple microtissues (more discussions can be found in section "Approaches for Stretching Three-Dimensional Engineered Tissue Constructs”).

A key feature of the native ECM is the fibrous structure that is mainly determined by fibrous collagen, fibrin, fibronectin and elastin networks. Such fibrous structures have been found to dramatically contribute to control ECM mechanical properties such as strain-stiffening and viscoelasticity (Prince and Kumacheva, 2019; van Oosten et al., 2019). Cells can sense fiber features (e.g., diameter, length, density and direction), actively remodel the fibrous networks via cell contraction, and respond by adjusting their contractility, migration, alignment and growth (Holmes et al., 2018; Brauer et al., 2019; Wang W. Y. et al., 2019). Moreover, recent studies have identified a particular important role of the fibrous networks in long-distance cell-cell communications and collective behaviors (Han et al., 2018; Sarker et al., 2019; Liu et al., 2020). While some reconstituted proteinbased biopolymers (e.g., type I collagen) can spontaneously self-assemble into fibrous structures under mild conditions, many widely used biopolymers [e.g., gelatin, sodium alginate, hyaluronic acid (HA)] and most synthetic hydrogels often lack fibrous structural features. Therefore, various approaches, e.g., self-assembly, phase separation and electrospinning, have been developed to generate synthetic fibrous constructs to mimic the architecture of fibrous ECMs (Zhao et al., 2015; Prince and Kumacheva, 2019). An excellent example is the electrospun HA-based fibrous hydrogels, which have been applied to study the roles of local fiber recruitment and fiber mechanics on cell spreading, proliferation, focal adhesion signaling and myofibroblast differentiation (Kim et al., 2013; Baker et al., 2015; Cao et al., 2017; Davidson et al., 2019). Interestingly, mechanical stretch cannot only direct the organization of single fibrous network but also regulate the interactions between both cell-matrix and different fibrous components (Vader et al., 2009; Kubow et al., 2015). Particularly, mechanical stretch has been found to modulate enzymatic degradation of collagen by sequestrating cleavage sites on collagen fibers (Bhole et al., 2009; Ghazanfari et al., 2016; Gaul et al., 2018). These further emphasize the importance of using fibrous hydrogels when engineering the stretching microenvironment of cells.

\section{Biochemical Considerations}

Biochemical cues have been extensively investigated in cell biology and tissue engineering. Mechanical stimuli can cooperatively or oppositely work with biochemical cues to orchestrate cell behavior (Salameh et al., 2010; Wan et al., 2019). From the perspective of biomaterial design, hydrogels may provide some specific biochemical properties that can influence the effect of mechanical stretch on cells. Specifically, hydrogels with different cell adhesive properties (usually determined by the presence of chemical functional groups or cell adhesion ligands on hydrogel networks) can show different capacities in transmitting mechanical forces or strains to cells encapsulated in them. Generally, the higher affinity between hydrogels and cells, the more efficiency of transmitting mechanical forces or strains by the hydrogels. This could be a dominant role of ECM sub-types and different biochemically modified hydrogels in regulating the responses of cells to mechanical stretch (Atance et al., 2004; Watson et al., 2014).

On the other hand, hydrogels can be engineered to sequester or immobilize growth factors by mimicking the performance of some ECM macromolecules, such as glycosaminoglycans (GAGs) (Gama et al., 2006; Lienemann et al., 2012; Hettiaratchi et al., 2016). These growth factors can be released and activated in response to mechanical stretching of hydrogels induced by cell contractile forces or external mechanical loadings, thus playing important roles in regulating cell mechanobiological responses. As a typical example, transforming growth factor- $\beta 1$ (TGF- $\beta 1$, a polypeptide cytokine belonging to the TGF superfamily that performs many functions in many cell types) is generally secreted and stored in the matrix as part of a large latent complex bound to the latent TGF- $\beta$ binding protein (LTBP). When the applied mechanical stretching is above a certain threshold, TGF- $\beta 1$ can be liberated and activated, establishing a mechanical checkpoint and contributing to many biological processes such as the progression of tissue repair and fibrosis (Maeda et al., 2011; Hinz, 2015; Froese et al., 2016; Walker et al., 2020).

\section{APPROACHES FOR STRETCHING THREE-DIMENSIONAL ENGINEERED TISSUE CONSTRUCTS}

While widely used for engineering 3D tissue constructs, it is still challenging to stretch cell-encapsulating hydrogels in a controllable way. Nevertheless, significant efforts have been made to anchor and actuate hydrogels for mechanically stretching hydrogel-based 3D engineered tissue constructs (Figure 4).

\section{Anchoring Approaches}

To enable mechanical stretching, engineered tissue constructs need to be anchored first to prevent unexpected slipping movement. Since 3D engineered tissue constructs are usually constructed by encapsulating cells into hydrogels, it is a big challenge to anchor such hydrogels. Unlike elastomers and rubbers that can be easily clamped for mechanical stretching tests, hydrogels used for engineering 3D tissue constructs are usually difficult to be anchored with conventional clamps. This is mainly due to their highly hydrated and relatively soft properties that make them susceptible to slippage, deformation or breakage under clamping and stretching (Tomei et al., 2009; Galie and Stegemann, 2011). To robustly anchor hydrogels, various approaches have been explored that can be generally classified into chemical anchoring and physical anchoring.

In chemical anchoring, hydrogels are usually covalently bonded to modified or activated anchoring surfaces during crosslinking. For example, GelMA provides reactive methacrylic groups that can be photo-crosslinked to 3(trimethoxysilyl)propyl methacrylate-modified glass substrates when exposed to ultraviolet light in the presence of photoinitiators (Van den Bulcke et al., 2000; Nichol et al., 2010; Hsieh et al., 2014). However, such approach is only 
A Ring-like hydrogel tissue construct
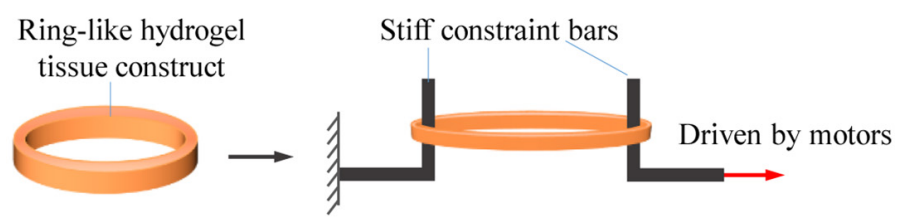

C

Stretchable membrane

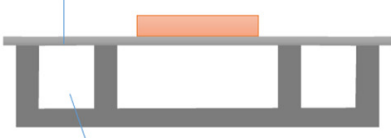

Side chamber

D

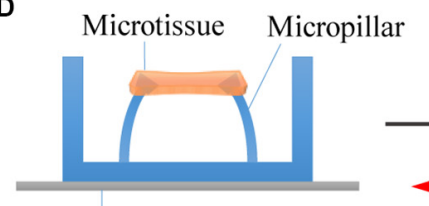

Stretchable membrane

$\mathbf{F}$

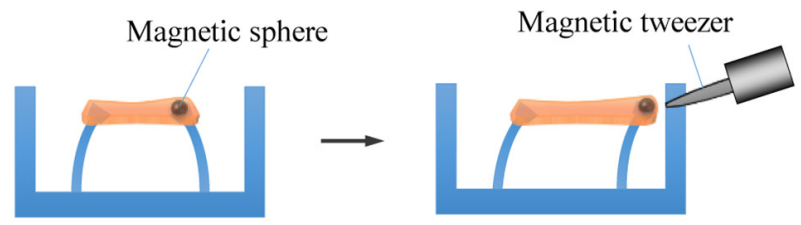

Magnetic field applied
B

Hydrogel tissue construct

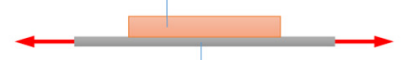

Membrane stretching driven by motors

E

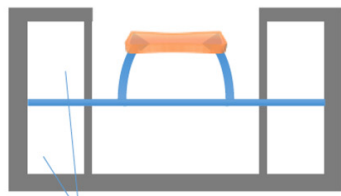

Side chamber

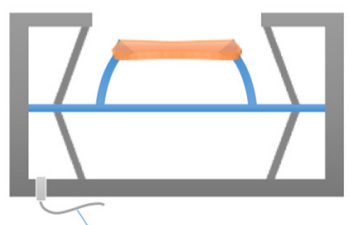

Vacuum applied
G

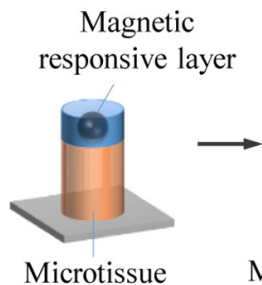

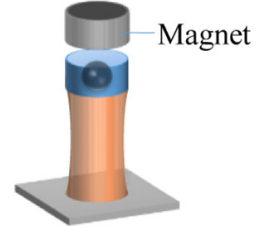

Magnetic field applied

FIGURE 4 | Representative approaches for stretching 3D engineered tissue constructs. (A) Hydrogel tissue constructs are fabricated into macroscale ring-like shapes, physically anchored with two stiff rods, and actuated to undergo stretching by using motor-driven approach. (B) Hydrogel tissue constructs are chemically bonded on stretchable membranes that are driven to stretch by using step motors. (C) Hydrogel tissue constructs are chemically bonded on stretchable membranes that are driven to stretch by applying vacuum pressure. (D) Hydrogel microtissue constructs are constrained by elastic micropillars. The distance between the micropillars changes when the underlying elastomeric membranes are stretched by either motor-driven or pneumatic actuation approaches, leading to deformation of the constrained microtissues. (E) Pneumatic actuation of micropillar-anchored microtissues by applying vacuum pressure to the side chambers of microtissues. (F) The microtissues are magnetically actuated by applying a non-uniform magnetic field to attract the magnetic microspheres fixed to the micropillars. (G) Enabling magnetic actuation by fabricating magnetic responsive layer onto photopatterned microtissues that chemically anchored on glass substrates.

applicable to some specific types of hydrogels. Similar approach has been applied for achieving tough bonding of hydrogels to amino-silane functionalized substrates of diverse solids by using EDC-Sulfo NHS chemistry (Yuk et al., 2016). However, it could not be used in the presence of cells due to the involvement of toxic chemicals and/or harsh conditions. While certain adhesives can chemically bond hydrogels to anchoring surfaces, this strategy involves the issues of weak bonding, low biocompatibility and/or slow adhesion formation (Pang et al., 2010; Mihic et al., 2014). Recently, Yuk et al. (2019) developed an interesting dry double-sided tape (DST) for rapid and strong adhesion of wet tissues and devices. Such DST could be employed for anchoring hydrogels in the presence of cells.

In contrast to chemical anchoring, physical anchoring does not apply chemical crosslinking but uses physical constraint to anchor hydrogels. For macroscale tissue constructs, this can be achieved by special designs (e.g., card slot and/or porous designs) of the anchors (Roeder et al., 2002; Gould et al., 2012). In the card slot design, the ends of the hydrogels are fabricated into designed shapes that can be physically locked by card slot anchors. This method, however, can be only used for stiff enough hydrogels. In the porous design, hydrogel precursor solution is firstly allowed to infiltrate into porous anchors and then crosslinked to form hydrogels with the ends integrated with the porous anchors. Both card slot and porous designs could involve troublesome operations and are not suitable for small-scale hydrogel tissue constructs. In addition, hydrogel tissue constructs have also been fabricated into ring- or runway-like shapes, which can then be simply hitched by two rods or pins for further mechanical stretching (Wakatsuki et al., 2000; Zimmermann et al., 2000, 2002; Berry et al., 2003; Asnes et al., 2006; Lee et al., 2012; Rinoldi et al., 2019). Inspired by this, and through tactfully exploiting the phenomenon of cell-induced collagen remodeling, Legant et al. (2009) developed a micropillar-based 
geometrical confinement approach that enables high-throughput fabrication of constrained microscale tissue constructs (i.e., engineered microtissues) of cell-encapsulating collagens. The custom-designed elastic micropillars (termed as microfabricated tissue gauges) are not only used to constrain the engineered microtissues but also to report forces generated by them in real time. Such approach has attracted great interests in the past decade (Jason et al., 2014; Liu et al., 2014; Mills et al., 2017; Ronaldson-Bouchard et al., 2018; Chen and Zhao, 2019). Recently, a similar approach has been reported by using elastic microwires instead of micropillars to constrain and monitor microtissues, showing great promises in heteropolar microtissue construction and disease modeling (Mastikhina et al., 2019; Wang E. Y. et al., 2019; Zhao Y. et al., 2019).

\section{Actuation Approaches}

When anchored, hydrogels can be actuated to undergo deformation, generating stretch stimulus to the encapsulated cells. While various actuation approaches have been developed to stretch single or monolayer cells, certain of them have not been adopted for stretching hydrogel-based 3D tissue constructs, mainly due to their limited driving force or poor strain controllability. Currently, the main approaches for driving hydrogel deformation can be generally classified into three types: motor-driven approach, pneumatic actuation, and magnetic actuation (Table $\mathbf{1}$ ).

Early studies that stretch macroscale tissue constructs usually use custom-designed motor-driven systems. Specifically, hydrogels encapsulating cells are anchored by clamps or stiff bars, which are connected to driving motors. The movement of driving motors thus leads to the deformation of cell-laden hydrogels (Fink et al., 2000; Wakatsuki et al., 2000; Powell et al., 2002). This approach is particularly suitable for uniaxial stretching. Biaxial stretching can also be achieved by perpendicularly equipping two driving motors, providing that the hydrogel tissue constructs are appropriately anchored. Benefit from the advantages of driving motors, such approach allows multiple loading modes, and precise control over strain amplitude and strain rate. Moreover, it is readily to incorporate mechanical transducers for measuring tensile forces. However, the physical contact between the driving system and the cell culture medium may involve the potential of contamination. In addition, it is suitable for engineering large tissue constructs but difficult to meet miniaturization and high-throughput requirements for drug screening applications.

Compared to directly stretching hydrogels, stretching elastomeric membranes is easier to implement and may avoid direct contact with cell culture medium. When chemically anchored on an elastomeric membrane, hydrogel tissue constructs can undergo deformation with the membrane, which can be achieved by using either motor-driven or pneumatic actuation approaches (Riehl et al., 2012; Doryab et al., 2019). Due to the substantial advantage of simple setup, pneumatic actuation has been commonly used (as represented by pneumatic commercial Flexcell ${ }^{\circledR}$ device), particularly in generating biaxial (radial and circumferential) tensile strains. Depending on how the systems are configured, both positive and negative pressures can be employed. However, conventional configurations with hydrogels bounding on an elastomeric membrane could suffer from several limitations such as nonuniform strain distribution (strain magnitude changes with distance from the center of the membrane), limited oxygen and nutrient diffusion as hampered by the bounding membrane, and low throughput (Riehl et al., 2012). In addition, pneumatic actuator may be limited in actuation rate due to the effect of air compressibility.

With the development of microengineering technologies, significant progress has been made by combing elastomeric membranes and elastic micropillars. In this case, hydrogel microtissue constructs are not directly stick to the elastomeric membranes but constrained by the elastic micropillars. The distance between the micropillars changes when the underlying elastomeric membranes are stretched by either motor-driven (Asmani et al., 2018; Chen et al., 2019) or pneumatic actuation (Asmani et al., 2019; van Kelle et al., 2019), leading to deformation of the constrained microtissues. Alternatively, pneumatic actuation of micropillar-anchored microtissues can be also realized by applying vacuum pressure to the side chambers of microtissues (Walker et al., 2018, 2019), similar to the actuation system developed for 2D cell culture (Huh et al., 2010). These approaches allow simultaneous stretching of multiple microtissues, and enable the measurement of microtissue contraction forces at the same time by following micropillar deflection.

TABLE 1 | A brief comparison and summary of the main actuation approaches.

Approaches

Motor-driven approach

\section{Comments}

Advantages: particularly suitable for uniaxial stretching and for engineering large tissue constructs, allow multiple loading modes and precise control over strain amplitude and strain rate

Disadvantages: potential contamination, difficult to simultaneously meet miniaturization, compartmentalization and high-throughput requirements

Advantages: simple setup, readily to incorporate with microfluidic technologies

Disadvantages: limited in actuation rate, could suffer from non-uniform strain distribution

Advantages: enable actuation in a non-contact and remote way, with the ability to measure microtissue stiffness and to change boundary stiffness in real time

Disadvantages: could be cumbersome to design and integrate the magnetic actuation system, potential unwanted magnetic effect on cells 
What is more, when fixing magnetic microspheres to the micropillars, the microtissues can be magnetically actuated in a non-contact and remote way by applying a non-uniform magnetic field to attract the microspheres (Zhao et al., 2013). This eliminates the actuation and even the use of elastomeric membranes. Similar approach has been developed by fabricating magnetic responsive layer onto photopatterned microtissues that are chemically anchored on glass substrates, which enables magnetic actuation without the complicated fabrication of micropillars (Li et al., 2016a,b). Custom magnetic tweezers have been used to selectively actuate a single microtissue or micropillar (Bose et al., 2018). To allow simultaneous actuation of multiple microtissues, custom-assembled magnet arrays and electrodeposited bar magnetics have been developed ( $\mathrm{Xu}$ et al., 2015; Li et al., 2016b). Compared to motor-driven approach and pneumatic actuation, magnetic actuation brings some additional important benefits such as the ability to measure microtissue stiffness and to change boundary stiffness (i.e., the effective bending stiffness of the micropillars) in real time (Zhao et al., 2014; Kural and Billiar, 2016; Rodriguez et al., 2019). A potential limitation for magnetic actuation is that it could be cumbersome to design and integrate the magnetic actuation system. In addition, a strong magnetic field could be required in certain conditions to achieve high strain amplitude, which may impose unwanted magnetic effect on cells.

\section{CONCLUDING REMARKS AND PERSPECTIVES}

An increasing interest has been put on the engineering of $3 \mathrm{D}$ cell microenvironment. As an essential cue for the survival, growth and functional performance of many types of cells, mechanical stretch is required but difficult to control in three dimensions. While remarkable progresses have been made in recent years, much work remains to be done.

First, hydrogels used for supporting cell stretching and culture in 3D usually have too simplified composition and poor controlled properties. The influences of hydrogel composition and properties on cell responses to mechanical stretching have been seldom investigated, despite the fact that hydrogels can provide diverse important cues for regulating cell behaviors (Atance et al., 2004; Watson et al., 2014). Second, most of the current studies have used lab-specific stretching devices without strict control and characterization of strain profiles in hydrogels, making it difficult to precisely regulate cell behaviors and compare the results of different studies. It is therefore

\section{REFERENCES}

Asmani, M., Kotei, C., Hsia, I., Marecki, L., Wang, T., Zhou, C., et al. (2019). Cyclic stretching of fibrotic microtissue array for evaluation of anti-fibrosis drugs. Cell. Mol. Bioeng. 12, 529-540. doi: 10.1007/s12195-019-00590-3

Asmani, M., Velumani, S., Li, Y., Wawrzyniak, N., Hsia, I., Chen, Z., et al. (2018). Fibrotic microtissue array to predict anti-fibrosis drug efficacy. Nat. Commun. 9:2066. necessary to develop standardized stretching devices that can be easily adopted by different labs for programmable mechanical stretching of cells in three dimensions. Third, most of the reported stretching devices are designed to induce a single stretch parameter at a time, limiting simultaneous investigation of multiple stretch parameters. Although several stretching devices have been designed to simultaneously apply multiple stretch parameters, media is usually pooled among samples in these studies, complicating data analysis with paracrine signaling. Finally, methods based on advanced optical imaging have been widely used in characterizing cell responses to mechanical stretching (Fu et al., 2018). However, other methods such as those based on electrochemical (Liu Y. L. et al., 2016; Liu et al., 2017; Liu et al., 2019; Huang and Liu, 2020), impedance (Lind et al., 2017; Zhang et al., 2017; Liu et al., 2018), and current (Mannhardt et al., 2019) sensing, once extended, may be particularly useful in fast, real-time and high-content analysis of biological and mechanical events.

Currently, mechanical stretching has greatly promoted the engineering of 3D tissue constructs for regeneration, however, mechanotransduction studies on cell stretching have been mostly performed in two dimensions, thus limiting in-depth understanding of stretch mechanobiology in pathophysiological conditions. Moreover, mechanical stretching has been seldom considered in engineered microtissues that used for drug screening applications. Future efforts should be directed toward the development of more versatile and predictive $3 \mathrm{D}$ cell stretching models for mechanobiology and drug screening studies. We anticipate that it will be promising to integrate and take advantages of advanced biomaterials, actuators and microengineering technologies such as $3 \mathrm{D}$ printing, microfluidics, and microelectromechanical systems.

\section{AUTHOR CONTRIBUTIONS}

All authors listed have made a substantial, direct and intellectual contribution to the work, and approved it for publication.

\section{FUNDING}

This work was supported by the National Natural Science Foundation of China (11872298) and Visiting Scholar Foundation of Key Laboratory of Biorheological Science and Technology (Chongqing University), Ministry of Education (CQKLBST-2019-003).

Asnes, C. F., Marquez, J. P., Elson, E. L., and Wakatsuki, T. (2006). Reconstitution of the Frank-Starling mechanism in engineered heart tissues. Biophys. J. 91, 1800-1810. doi: 10.1529/biophysj.105.065961

Atance, J., Yost, M. J., and Carver, W. (2004). Influence of the extracellular matrix on the regulation of cardiac fibroblast behavior by mechanical stretch. J. Cell. Physiol. 200, 377-386. doi: 10.1002/jcp.20034

Babaei, B., Davarian, A., Lee, S.-L., Pryse, K. M., Mcconnaughey, W. B., Elson, E. L., et al. (2016). Remodeling by fibroblasts alters the rate-dependent mechanical 
properties of collagen. Acta Biomater. 37, 28-37. doi: 10.1016/j.actbio.2016.03. 034

Bai, L., Mesgarzadeh, S., Ramesh, K. S., Huey, E. L., Liu, Y., Gray, L. A., et al. (2019). Genetic identification of vagal sensory neurons that control feeding. Cell 179, 1129-1143.e23.

Baker, B. M., Trappmann, B., Wang, W. Y., Sakar, M. S., Kim, I. L., Shenoy, V. B., et al. (2015). Cell-mediated fibre recruitment drives extracellular matrix mechanosensing in engineered fibrillar microenvironments. Nat. Mater. 14, 1262-1268. doi: $10.1038 /$ nmat 4444

Balestrini, J. L., and Billiar, K. L. (2009). Magnitude and duration of stretch modulate fibroblast remodeling. J. Biomech. Eng. 131:051005.

Ban, E., Franklin, J. M., Nam, S., Smith, L. R., Wang, H., Wells, R. G., et al. (2018). Mechanisms of plastic deformation in collagen networks induced by cellular forces. Biophys. J. 114, 450-461. doi: 10.1016/j.bpj.2017.11.3739

Bauer, A., Gu, L., Kwee, B., Li, A., Dellacherie, M., Celiz, A. D., et al. (2017). Hydrogel substrate stress-relaxation regulates the spreading and proliferation of mouse myoblasts. Acta Biomater. 62, 82-90. doi: 10.1016/j.actbio.2017. 08.041

Berry, C. C., Shelton, J. C., Bader, D. L., and Lee, D. A. (2003). Influence of external uniaxial cyclic strain on oriented fibroblast-seeded collagen gels. Tissue Engin. 9, 613-624. doi: 10.1089/107632703768247313

Bhole, A. P., Flynn, B. P., Liles, M., Saeidi, N., Dimarzio, C. A., and Ruberti, J. W. (2009). Mechanical strain enhances survivability of collagen micronetworks in the presence of collagenase: implications for load-bearing matrix growth and stability. Philos. Trans. R. Soc. Lond. A 367, 3339-3362. doi: 10.1098/rsta.2009. 0093

Bonnevie, E. D., Gullbrand, S. E., Ashinsky, B. G., Tsinman, T. K., Elliott, D. M., Chao, P.-H. G., et al. (2019). Aberrant mechanosensing in injured intervertebral discs as a result of boundary-constraint disruption and residual-strain loss. Nat. Biomed. Eng. 3, 998-1008. doi: 10.1038/s41551-019-0458-4

Bose, P., Eyckmans, J., Nguyen, T. D., Chen, C. S., and Reich, D. H. (2018). Effects of geometry on the mechanics and alignment of three-dimensional engineered microtissues. ACS Biomater. Sci. Eng. 5, 3843-3855. doi: 10.1021/ acsbiomaterials.8b01183

Boudou, T., Andersen, T., and Balland, M. (2019). On the spatiotemporal regulation of cell tensional state. Exp. Cell Res. 378, 113-117. doi: 10.1016/j. yexcr.2019.02.018

Brauer, E., Lippens, E., Klein, O., Nebrich, G., Schreivogel, S., Korus, G., et al. (2019). Collagen fibrils mechanically contribute to tissue contraction in an in vitro wound healing scenario. Adv. Sci. 6:1801780. doi: 10.1002/advs. 201801780

Brown, R. A., Prajapati, R., Mcgrouther, D. A., Yannas, I. V., and Eastwood, M. (1998). Tensional homeostasis in dermal fibroblasts: mechanical responses to mechanical loading in three-dimensional substrates. J. Cell. Physiol. 175, 323-332. doi: 10.1002/(sici)1097-4652(199806)175:3<323::aid-jcp10>3.0. co;2-6

Burla, F., Tauber, J., Dussi, S., Van Der Gucht, J., and Koenderink, G. H. (2019). Stress management in composite biopolymer networks. Nat. Phys. 15, 549-553. doi: 10.1038/s41567-019-0443-6

Caliari, S. R., Vega, S. L., Kwon, M., Soulas, E. M., and Burdick, J. A. (2016). Dimensionality and spreading influence MSC YAP/TAZ signaling in hydrogel environments. Biomaterials 103, 314-323. doi: 10.1016/j.biomaterials.2016.06. 061

Cambré, I., Gaublomme, D., Burssens, A., Jacques, P., Schryvers, N., De Muynck, A., et al. (2018). Mechanical strain determines the site-specific localization of inflammation and tissue damage in arthritis. Nat. Commun. 9:4613.

Cantini, M., Donnelly, H., Dalby, M. J., and Salmeron-Sanchez, M. (2020). The plot thickens: the emerging role of matrix viscosity in cell mechanotransduction. Adv. Healthc. Mater. 9:1901259. doi: 10.1002/adhm.201901259

Cao, X., Ban, E., Baker, B. M., Lin, Y., Burdick, J. A., Chen, C. S., et al. (2017). Multiscale model predicts increasing focal adhesion size with decreasing stiffness in fibrous matrices. Proc. Natl. Acad. Sci. U.S.A. 114, E4549-E4555.

Charrier, E. E., Pogoda, K., Wells, R. G., and Janmey, P. A. (2018). Control of cell morphology and differentiation by substrates with independently tunable elasticity and viscous dissipation. Nat. Commun. 9:449.

Chaudhuri, O., Gu, L., Darnell, M., Klumpers, D., Bencherif, S. A., Weaver, J. C., et al. (2015). Substrate stress relaxation regulates cell spreading. Nat. Commun. $6: 6364$.
Chaudhuri, O., Gu, L., Klumpers, D., Darnell, M., Bencherif, S. A., Weaver, J. C., et al. (2016). Hydrogels with tunable stress relaxation regulate stem cell fate and activity. Nat. Mater. 15, 326-334. doi: 10.1038/nmat4489

Chen, K., Vigliotti, A., Bacca, M., Mcmeeking, R. M., Deshpande, V. S., and Holmes, J. W. (2018). Role of boundary conditions in determining cell alignment in response to stretch. Proc. Natl. Acad. Sci. U.S.A. 115, 986-991. doi: 10.1073/pnas.1715059115

Chen, Z., Lu, J., Zhang, C., Hsia, I., Yu, X., Marecki, L., et al. (2019). Microclot array elastometry for integrated measurement of thrombus formation and clot biomechanics under fluid shear. Nat. Commun. 10:2051.

Chen, Z., and Zhao, R. (2019). Engineered tissue development in biofabricated 3D geometrical confinement-a review. ACS Biomat. Sci. Eng. 5, 3688-3702. doi: 10.1021/acsbiomaterials.8b01195

Cheng, B., Lin, M., Huang, G., Li, Y., Ji, B., Genin, G. M., et al. (2017). Cellular mechanosensing of the biophysical microenvironment: a review of mathematical models of biophysical regulation of cell responses. Phys. Life Rev. 2, 88-119. doi: 10.1016/j.plrev.2017.06.016

Choi, N. W., Cabodi, M., Held, B., Gleghorn, J. P., Bonassar, L. J., and Stroock, A. D. (2007). Microfluidic scaffolds for tissue engineering. Nat. Mater. 6, 908-915.

Cui, Y., Hameed, F. M., Yang, B., Lee, K., Pan, C. Q., Park, S., et al. (2015). Cyclic stretching of soft substrates induces spreading and growth. Nat. Commun. 6:6333.

Das, R. K., Gocheva, V., Hammink, R., Zouani, O. F., and Rowan, A. E. (2016). Stress-stiffening-mediated stem-cell commitment switch in soft responsive hydrogels. Nat. Mater. 15, 318-325. doi: 10.1038/nmat4483

Davidson, M., Song, K., Lee, M. H., Llewellyn, J., Du, Y., Baker, B., et al. (2019). Engineered fibrous networks to investigate the influence of fiber mechanics on myofibroblast differentiation. ACS Biomat. Sci. Eng. 5, 3899-3908. doi: 10.1021/acsbiomaterials.8b01276

Davidson, M. D., Burdick, J. A., and Wells, R. G. (2020). Engineered biomaterial platforms to study fibrosis. Adv. Healthc. Mater. 9:1901682. doi: 10.1002/adhm. 201901682

Doryab, A., Tas, S., Taskin, M. B., Yang, L., Hilgendorff, A., Groll, J., et al. (2019). Evolution of bioengineered lung models: recent advances and challenges in tissue mimicry for studying the role of mechanical forces in cell biology. $A d v$. Funct. Mater. 29:1903114. doi: 10.1002/adfm.201903114

Engler, A. J., Sen, S., Sweeney, H. L., and Discher, D. E. (2006). Matrix elasticity directs stem cell lineage specification. Cell 126, 677-689. doi: 10.1016/j.cell. 2006.06.044

Eyckmans, J., and Chen, C. S. (2017). 3D culture models of tissues under tension. J. Cell Sci. 130:63. doi: 10.1242/jcs.198630

Faust, U., Hampe, N., Rubner, W., Kirchgeßner, N., Safran, S., Hoffmann, B., et al. (2011). Cyclic stress at $\mathrm{mHz}$ frequencies aligns fibroblasts in direction of zero strain. PLoS One 6:e28963. doi: 10.1371/journal.pone.0028963

Feng, Q., Wei, K., Lin, S., Xu, Z., Sun, Y., Shi, P., et al. (2016). Mechanically resilient, injectable, and bioadhesive supramolecular gelatin hydrogels crosslinked by weak host-guest interactions assist cell infiltration and in situ tissue regeneration. Biomaterials 101, 217-228. doi: 10.1016/j.biomaterials.2016.05. 043

Fink, C., ErgÜn, S., Kralisch, D., Remmers, U., Weil, J., and Eschenhagen, T. (2000). Chronic stretch of engineered heart tissue induces hypertrophy and functional improvement. FASEB J. 14, 669-679. doi: 10.1096/fasebj.14.5.669

Fletcher, D. A., and Mullins, R. D. (2010). Cell mechanics and the cytoskeleton. Nature 463, 485-492.

Froese, A. R., Shimbori, C., Bellaye, P.-S., Inman, M., Obex, S., Fatima, S., et al. (2016). Stretch-induced activation of transforming growth factor- $\beta 1$ in pulmonary fibrosis. Am. J. Respir. Crit. Care Med. 194, 84-96. doi: 10.1164/ rccm.201508-1638oc

Fu, F., Shang, L., Chen, Z., Yu, Y., and Zhao, Y. (2018). Bioinspired living structural color hydrogels. Sci. Robot. 3:eaar8580. doi: 10.1126/scirobotics.aar8580

Galie, P. A., and Stegemann, J. P. (2011). Simultaneous application of interstitial flow and cyclic mechanical strain to a three-dimensional cell-seeded hydrogel. Tissue Eng. Part C Methods 17, 527-536. doi: 10.1089/ten.tec.2010.0547

Gama, C. I., Tully, S. E., Sotogaku, N., Clark, P. M., Rawat, M., Vaidehi, N., et al. (2006). Sulfation patterns of glycosaminoglycans encode molecular recognition and activity. Nat. Chem. Biol. 2, 467-473. doi: 10.1038/nchembio810

Gaul, R. T., Nolan, D. R., Ristori, T., Bouten, C. V. C., Loerakker, S., and Lally, C. (2018). Strain mediated enzymatic degradation of arterial tissue: Insights into 
the role of the non-collagenous tissue matrix and collagen crimp. Acta Biomater. 77, 301-310. doi: 10.1016/j.actbio.2018.06.037

Ghazanfari, S., Driessen-Mol, A., Bouten, C. V. C., and Baaijens, F. P. T. (2016). Modulation of collagen fiber orientation by strain-controlled enzymatic degradation. Acta Biomater. 35, 118-126. doi: 10.1016/j.actbio.2016.02.033

Giulitti, S., Zambon, A., Michielin, F., and Elvassore, N. (2016). Mechanotransduction through substrates engineering and microfluidic devices. Curr. Opin. Chem. Eng. 11, 67-76. doi: 10.1016/j.coche.2016.01.010

Gong, Z., Szczesny, S. E., Caliari, S. R., Charrier, E. E., Chaudhuri, O., Cao, X., et al. (2018). Matching material and cellular timescales maximizes cell spreading on viscoelastic substrates. Proc. Natl. Acad. Sci. U.S.A. 115, E2686-E2695.

Gould, R. A., Chin, K., Santisakultarm, T. P., Dropkin, A., Richards, J. M., Schaffer, C. B., et al. (2012). Cyclic strain anisotropy regulates valvular interstitial cell phenotype and tissue remodeling in three-dimensional culture. Acta Biomater. 8, 1710-1719. doi: 10.1016/j.actbio.2012.01.006

Guan, N. N., Sharma, N., Hallén-Grufman, K., Jager, E. W. H., and Svennersten, K. (2018). The role of ATP signalling in response to mechanical stimulation studied in T24 cells using new microphysiological tools. J. Cell Mol. Med. 22, 2319-2328. doi: 10.1111/jcmm.13520

Guven, S., Chen, P., Inci, F., Tasoglu, S., Erkmen, B., and Demirci, U. (2015). Multiscale assembly for tissue engineering and regenerative medicine. Trends Biotechnol. 33, 269-279. doi: 10.1016/j.tibtech.2015.02.003

Hall, M. S., Alisafaei, F., Ban, E., Feng, X., Hui, C.-Y., Shenoy, V. B., et al. (2016). Fibrous nonlinear elasticity enables positive mechanical feedback between cells and ECMs. Proc. Natl. Acad. Sci. U.S.A. 113, 14043-14048. doi: 10.1073/pnas. 1613058113

Han, Y. L., Pegoraro, A. F., Li, H., Li, K., Yuan, Y., Xu, G., et al. (2020). Cell swelling, softening and invasion in a three-dimensional breast cancer model. Nat. Phys. 16, 101-108. doi: 10.1038/s41567-019-0680-8

Han, Y. L., Ronceray, P., Xu, G., Malandrino, A., Kamm, R. D., Lenz, M., et al. (2018). Cell contraction induces long-ranged stress stiffening in the extracellular matrix. Proc. Natl. Acad. Sci. U.S.A. 115, 4075-4080. doi: 10.1073/ pnas. 1722619115

He, L., Si, G., Huang, J., Samuel, A. D. T., and Perrimon, N. (2018). Mechanical regulation of stem-cell differentiation by the stretch-activated Piezo channel. Nature 555, 103-106. doi: 10.1038/nature25744

Hettiaratchi, M. H., Guldberg, R. E., and Mcdevitt, T. C. (2016). Biomaterial strategies for controlling stem cell fate via morphogen sequestration. J. Mater. Chem. B 4, 3464-3481. doi: $10.1039 / \mathrm{c} 5$ tb02575c

Hinz, B. (2015). The extracellular matrix and transforming growth factor- $\beta 1$ : tale of a strained relationship. Matrix Biol. 47, 54-65. doi: 10.1016/j.matbio.2015. 05.006

Holmes, D. F., Yeung, C.-Y. C., Garva, R., Zindy, E., Taylor, S. H., Lu, Y., et al. (2018). Synchronized mechanical oscillations at the cell-matrix interface in the formation of tensile tissue. Proc. Natl. Acad. Sci. U.S.A. 115, E9288-E9297.

Hong, S., Sycks, D., Chan, H. F., Lin, S., Lopez, G. P., Guilak, F., et al. (2015). 3D printing of highly stretchable and tough hydrogels into complex, cellularized structures. Adv. Mater. 27, 4035-4040. doi: 10.1002/adma.201501099

Hsieh, H.-Y., Camci-Unal, G., Huang, T.-W., Liao, R., Chen, T.-J., Paul, A., et al. (2014). Gradient static-strain stimulation in a microfluidic chip for 3D cellular alignment. Lab Chip 14, 482-493. doi: 10.1039/c3lc50884f

Hu, J., Li, Y., Hao, Y., Zheng, T., Gupta, S. K., Parada, G. A., et al. (2019). High stretchability, strength, and toughness of living cells enabled by hyperelastic vimentin intermediate filaments. Proc. Natl. Acad. Sci. U.S.A. 116, 17175-17180. doi: 10.1073/pnas.1903890116

Huang, D., Huang, Y., Xiao, Y., Yang, X., Lin, H., Feng, G., et al. (2019). Viscoelasticity in natural tissues and engineered scaffolds for tissue reconstruction. Acta Biomater. 97, 74-92. doi: 10.1016/j.actbio.2019.08.013

Huang, G., Xu, F., Genin, G. M., and Lu, T. J. (2019). Mechanical microenvironments of living cells: a critical frontier in mechanobiology. Acta Mech. Sin. 35, 265-269. doi: 10.1007/s10409-019-00854-1

Huang, G., Li, F., Zhao, X., Ma, Y., Li, Y., Lin, M., et al. (2017). Functional and biomimetic materials for engineering of the three-dimensional cell microenvironment. Chem. Rev. 117, 12764-12850. doi: 10.1021/acs.chemrev. $7 \mathrm{~b} 00094$

Huang, G., Wang, S., He, X., Zhang, X., Lu, T. J., and Xu, F. (2013). Helical spring template fabrication of cell-laden microfluidic hydrogels for tissue engineering. Biotechnol. Bioeng. 110, 980-989. doi: 10.1002/bit.24764
Huang, G., Zhang, X., Xiao, Z., Zhang, Q., Zhou, J., Xu, F., et al. (2012). Cellencapsulating microfluidic hydrogels with enhanced mechanical stability. Soft Matter 8, 10687-10694. doi: 10.1039/c2sm26126j

Huang, G. Y., Zhou, L. H., Zhang, Q. C., Chen, Y. M., Sun, W., Xu, F., et al. (2011). Microfluidic hydrogels for tissue engineering. Biofabrication 3:012001.

Huang, W.-H., and Liu, Y.-L. (2020). Stretchable electrochemical sensors for cell and tissue detection. Angew. Chem. Int. Ed. doi: 10.1002/anie.202007754

Huh, D., Matthews, B. D., Mammoto, A., Montoya-Zavala, M., Hsin, H. Y., and Ingber, D. E. (2010). Reconstituting organ-level lung functions on a chip. Science 328, 1662-1668. doi: 10.1126/science.1188302

Humphrey, J. D., Dufresne, E. R., and Schwartz, M. A. (2014). Mechanotransduction and extracellular matrix homeostasis. Nat. Rev. Mol. Cell Biol. 15, 802-812. doi: 10.1038/nrm3896

Imboden, M., De Coulon, E., Poulin, A., Dellenbach, C., Rosset, S., Shea, H., et al. (2019). High-speed mechano-active multielectrode array for investigating rapid stretch effects on cardiac tissue. Nat. Commun. 10:834.

Jason, W. M., Sara, S. N., Aarash, S., Lewis, A. R., Aric, P., Yun, X., et al. (2014). Bioreactor for modulation of cardiac microtissue phenotype by combined static stretch and electrical stimulation. Biofabrication 6:024113. doi: 10.1088/17585082/6/2/024113

Jaspers, M., Dennison, M., Mabesoone, M. F. J., Mackintosh, F. C., Rowan, A. E., and Kouwer, P. H. J. (2014). Ultra-responsive soft matter from strain-stiffening hydrogels. Nat. Commun. 5:5808.

Jiang, W., Niu, D., Wei, L., Ye, G., Wang, L., Liu, H., et al. (2018). Controllable actuation of photomechanical bilayer nanocomposites for in vitro cell manipulation. Carbon 139, 1048-1056.

Kamble, H., Barton, M. J., Jun, M., Park, S., and Nguyen, N.-T. (2016). Cell stretching devices as research tools: engineering and biological considerations. Lab Chip 16, 3193-3203. doi: 10.1039/c6lc00607h

Kim, D.-H., Wong, P. K., Park, J., Levchenko, A., and Sun, Y. (2009). Microengineered platforms for cell mechanobiology. Annu. Rev. Biomed. Eng. 11, 203-233. doi: 10.1146/annurev-bioeng-061008-124915

Kim, I. L., Khetan, S., Baker, B. M., Chen, C. S., and Burdick, J. A. (2013). Fibrous hyaluronic acid hydrogels that direct MSC chondrogenesis through mechanical and adhesive cues. Biomaterials 34, 5571-5580. doi: 10.1016/j.biomaterials. 2013.04.004

Kim, J., Feng, J., Jones, C. A. R., Mao, X., Sander, L. M., Levine, H., et al. (2017). Stress-induced plasticity of dynamic collagen networks. Nat. Commun. 8:842.

Kubow, K. E., Vukmirovic, R., Zhe, L., Klotzsch, E., Smith, M. L., Gourdon, D., et al. (2015). Mechanical forces regulate the interactions of fibronectin and collagen I in extracellular matrix. Nat. Commun. 6:8026.

Kural, M. H., and Billiar, K. L. (2016). Myofibroblast persistence with real-time changes in boundary stiffness. Acta Biomater. 32, 223-230. doi: 10.1016/j. actbio.2015.12.031

Kurpinski, K., Chu, J., Hashi, C., and Li, S. (2006). Anisotropic mechanosensing by mesenchymal stem cells. Proc. Natl. Acad. Sci. U.S.A. 103:16095. doi: 10.1073/ pnas. 0604182103

Landau, S., Ben-Shaul, S., and Levenberg, S. (2018). Oscillatory strain promotes vessel stabilization and alignment through fibroblast YAP-mediated mechanosensitivity. Adv. Sci. 5:1800506. doi: 10.1002/advs.201800506

Latorre, E., Kale, S., Casares, L., Gómez-González, M., Uroz, M., Valon, L., et al. (2018). Active superelasticity in three-dimensional epithelia of controlled shape. Nature 563, 203-208. doi: 10.1038/s41586-018-0671-4

Lee, S.-L., Nekouzadeh, A., Butler, B., Pryse, K. M., Mcconnaughey, W. B., Nathan, A. C., et al. (2012). Physically-induced cytoskeleton remodeling of cells in threedimensional culture. PLoS One 7:e45512. doi: 10.1371/journal.pone.0045512

Legant, W. R., Pathak, A., Yang, M. T., Deshpande, V. S., Mcmeeking, R. M., and Chen, C. S. (2009). Microfabricated tissue gauges to measure and manipulate forces from 3D microtissues. Proc. Natl. Acad. Sci. U.S.A. 106, 10097-10102. doi: 10.1073/pnas.0900174106

Li, J., Illeperuma, W. R. K., Suo, Z., and Vlassak, J. J. (2014). Hybrid hydrogels with extremely high stiffness and toughness. ACS Macro Lett. 3, 520-523. doi: $10.1021 / \mathrm{mz} 5002355$

Li, Y., Huang, G., Zhang, X., Wang, L., Du, Y., Lu, T. J., et al. (2014). Engineering cell alignment in vitro. Biotechnol. Adv. 32, 347-365. doi: 10.1016/j.biotechadv. 2013.11.007

Li, L., Eyckmans, J., and Chen, C. S. (2017). Designer biomaterials for mechanobiology. Nat. Mater. 16:1164. doi: 10.1038/nmat5049 
Li, Y., Guo, F., Hao, Y., Gupta, S. K., Hu, J., Wang, Y., et al. (2019). Helical nanofiber yarn enabling highly stretchable engineered microtissue. Proc. Natl. Acad. Sci. U.S.A. 116:9245. doi: 10.1073/pnas.1821617116

Li, Y., Huang, G., Gao, B., Li, M., Genin, G. M., Lu, T. J., et al. (2016a). Magnetically actuated cell-laden microscale hydrogels for probing straininduced cell responses in three dimensions. NPG Asia Mater. 8:e238. doi: 10.1038/am.2015.148

Li, Y., Huang, G., Li, M., Wang, L., Elson, E. L., Lu, T. J., et al. (2016b). An approach to quantifying 3D responses of cells to extreme strain. Sci. Rep. 6:19550.

Li, Y., Poon, C. T., Li, M., Lu, T. J., Pingguan-Murphy, B., and Xu, F. (2015). Chinese-noodle-inspired muscle myofiber fabrication. Adv. Funct. Mater. 25, 5999-6008. doi: 10.1002/adfm.201502018

Licup, A. J., Münster, S., Sharma, A., Sheinman, M., Jawerth, L. M., Fabry, B., et al. (2015). Stress controls the mechanics of collagen networks. Proc. Natl. Acad. Sci. U.S.A. 112, 9573-9578. doi: 10.1073/pnas.1504258112

Lienemann, P. S., Lutolf, M. P., and Ehrbar, M. (2012). Biomimetic hydrogels for controlled biomolecule delivery to augment bone regeneration. Adv. Drug Deliv. Rev. 64, 1078-1089. doi: 10.1016/j.addr.2012.03.010

Lind, J. U., Busbee, T. A., Valentine, A. D., Pasqualini, F. S., Yuan, H., Yadid, M., et al. (2017). Instrumented cardiac microphysiological devices via multimaterial three-dimensional printing. Nat. Mater. 16, 303-308. doi: 10.1038/nmat 4782

Liu, H., Macqueen, L. A., Usprech, J. F., Maleki, H., Sider, K. L., Doyle, M. G., et al. (2018). Microdevice arrays with strain sensors for 3D mechanical stimulation and monitoring of engineered tissues. Biomaterials 172, 30-40. doi: 10.1016/j. biomaterials.2018.04.041

Liu, J., Zhang, D., Sha, B., Yin, P., Xu, Z., Liu, C., et al. (2014). Fabrication of a three-layer SU-8 mould with inverted T-shaped cavities based on a sacrificial photoresist layer technique. Biomed. Microdevices 16, 655-660. doi: 10.1007/ s10544-014-9868-y

Liu, L., Yu, H., Zhao, H., Wu, Z., Long, Y., Zhang, J., et al. (2020). Matrixtransmitted paratensile signaling enables myofibroblast-fibroblast cross talk in fibrosis expansion. Proc. Natl. Acad. Sci. U.S.A. 201910650.

Liu, Y.-L., Chen, Y., Fan, W.-T., Cao, P., Yan, J., Zhao, X.-Z., et al. (2019). Mechanical distension induces serotonin release from intestine as revealed by stretchable electrochemical sensing. Angew. Chem. Int. Ed. 59, 4075-4081. doi: 10.1002/anie.201913953

Liu, Y.-L., Jin, Z.-H., Liu, Y.-H., Hu, X.-B., Qin, Y., Xu, J.-Q., et al. (2016). Stretchable electrochemical sensor for real-time monitoring of cells and tissues. Angew. Chem. Int. Ed. 55, 4537-4541. doi: 10.1002/anie.201601276

Liu, Z., Wu, H., Jiang, K., Wang, Y., Zhang, W., Chu, Q., et al. (2016). MAPKmediated YAP activation controls mechanical-tension-induced pulmonary alveolar regeneration. Cell Rep. 16, 1810-1819. doi: 10.1016/j.celrep.2016.07. 020

Liu, Y.-L., Qin, Y., Jin, Z.-H., Hu, X.-B., Chen, M.-M., Liu, R., et al. (2017). A stretchable electrochemical sensor for inducing and monitoring cell mechanotransduction in real tme. Angew. Chem. Int. Ed. 56, 9454-9458. doi: 10.1002/anie. 201705215

Lou, J., Stowers, R., Nam, S., Xia, Y., and Chaudhuri, O. (2018). Stress relaxing hyaluronic acid-collagen hydrogels promote cell spreading, fiber remodeling, and focal adhesion formation in 3D cell culture. Biomaterials 154, 213-222. doi: 10.1016/j.biomaterials.2017.11.004

Maeda, T., Sakabe, T., Sunaga, A., Sakai, K., Rivera, A. L., Keene, D. R., et al. (2011). Conversion of mechanical force into TGF- $\beta$-mediated biochemical signals. Curr. Biol. 21, 933-941.

Mann, J. M., Lam, R. H. W., Weng, S., Sun, Y., and Fu, J. (2012). A silicone-based stretchable micropost array membrane for monitoring live-cell subcellular cytoskeletal response. Lab Chip 12, 731-740. doi: 10.1039/c2lc20896b

Mannhardt, I., Warncke, C., Trieu, H. K., Müller, J., and Eschenhagen, T. (2019). Piezo-bending actuators for isometric or auxotonic contraction analysis of engineered heart tissue. J. Tissue Eng. Regen. Med. 13, 3-11. doi: 10.1002/term. 2755

Mastikhina, O., Moon, B.-U., Williams, K., Hatkar, R., Gustafson, D., Mourad, O., et al. (2019). Human cardiac fibrosis-on-a-chip model recapitulates disease hallmarks and can serve as a platform for drug testing. Biomaterials 233:119741. doi: 10.1016/j.biomaterials.2019.119741

Maul, T. M., Chew, D. W., Nieponice, A., and Vorp, D. A. (2011). Mechanical stimuli differentially control stem cell behavior: morphology, proliferation, and differentiation. Biomech. Model. Mechanobiol. 10, 939-953. doi: 10.1007/ s10237-010-0285-8

Mihic, A., Li, J., Miyagi, Y., Gagliardi, M., Li, S.-H., Zu, J., et al. (2014). The effect of cyclic stretch on maturation and 3D tissue formation of human embryonic stem cell-derived cardiomyocytes. Biomaterials 35, 2798-2808. doi: 10.1016/j. biomaterials.2013.12.052

Mills, R. J., Titmarsh, D. M., Koenig, X., Parker, B. L., Ryall, J. G., Quaife-Ryan, G. A., et al. (2017). Functional screening in human cardiac organoids reveals a metabolic mechanism for cardiomyocyte cell cycle arrest. Proc. Natl. Acad. Sci. U.S.A. 114, E8372.

Ming, Z., Pang, Y., and Liu, J. (2020). Switching between elasticity and plasticity by network strength competition. Adv. Mater. 32:1906870. doi: 10.1002/adma. 201906870

Münster, S., Jawerth, L. M., Leslie, B. A., Weitz, J. I., Fabry, B., and Weitz, D. A. (2013). Strain history dependence of the nonlinear stress response of fibrin and collagen networks. Proc. Natl. Acad. Sci. U.S.A. 110, 12197-12202. doi: $10.1073 /$ pnas. 1222787110

Nam, S., Hu, K. H., Butte, M. J., and Chaudhuri, O. (2016a). Strain-enhanced stress relaxation impacts nonlinear elasticity in collagen gels. Proc. Natl. Acad. Sci. U.S.A. 113, 5492-5497. doi: 10.1073/pnas.1523906113

Nam, S., Lee, J., Brownfield, D. G., and Chaudhuri, O. (2016b). Viscoplasticity enables mechanical remodeling of matrix by cells. Biophys. J. 111, 2296-2308. doi: 10.1016/j.bpj.2016.10.002

Nichol, J. W., Koshy, S. T., Bae, H., Hwang, C. M., Yamanlar, S., and Khademhosseini, A. (2010). Cell-laden microengineered gelatin methacrylate hydrogels. Biomaterials 31, 5536-5544. doi: 10.1016/j.biomaterials.2010.03.064

Pang, Q., Zu, J. W., Siu, G. M., and Li, R. K. (2010). Design and development of a novel biostretch apparatus for tissue engineering. J. Biomech. Eng. 132:014503.

Panzetta, V., Fusco, S., and Netti, P. A. (2019). Cell mechanosensing is regulated by substrate strain energy rather than stiffness. Proc. Natl. Acad. Sci. U.S.A. 116:22004. doi: 10.1073/pnas.1904660116

Pei, D., Wang, M., Li, W., Li, M., Liu, Q., Ding, R., et al. (2020). Remodeling of aligned fibrous extracellular matrix by encapsulated cells under mechanical stretching. Acta Biomater. 112, 202-212. doi: 10.1016/j.actbio.2020.05.027

Polacheck, W. J., Li, R., Uzel, S. G. M., and Kamm, R. D. (2013). Microfluidic platforms for mechanobiology. Lab Chip 13, 2252-2267. doi: 10.1039/ c3lc41393d

Poulin, A., Imboden, M., Sorba, F., Grazioli, S., Martin-Olmos, C., Rosset, S., et al. (2018). An ultra-fast mechanically active cell culture substrate. Sci. Rep. 8:9895.

Poulin, A., Saygili Demir, C., Rosset, S., Petrova, T. V., and Shea, H. (2016). Dielectric elastomer actuator for mechanical loading of 2D cell cultures. Lab Chip 16, 3788-3794. doi: 10.1039/c6lc00903d

Powell, C. A., Smiley, B. L., Mills, J., and Vandenburgh, H. H. (2002). Mechanical stimulation improves tissue-engineered human skeletal muscle. Am. J. Physiol. Cell Physiol. 283, C1557-C1565.

Prince, E., and Kumacheva, E. (2019). Design and applications of man-made biomimetic fibrillar hydrogels. Nat. Rev. Mater. 4, 99-115. doi: 10.1038/s41578018-0077-9

Pryse, K. M., Nekouzadeh, A., Genin, G. M., Elson, E. L., and Zahalak, G. I. (2003). Incremental mechanics of collagen gels: new experiments and a new viscoelastic model. Ann. Biomed. Eng. 31, 1287-1296. doi: 10.1114/1.1615571

Qi, Y.-X., Qu, M.-J., Yan, Z.-Q., Zhao, D., Jiang, X.-H., Shen, B.-R., et al. (2010). Cyclic strain modulates migration and proliferation of vascular smooth muscle cells via Rho-GDI $\alpha$, Rac1, and p38 pathway. J. Cell. Biochem. 109, 906-914.

Qi, Y.-X., Yao, Q.-P., Huang, K., Shi, Q., Zhang, P., Wang, G.-L., et al. (2016). Nuclear envelope proteins modulate proliferation of vascular smooth muscle cells during cyclic stretch application. Proc. Natl. Acad. Sci. U.S.A. 113, 52935298. doi: 10.1073/pnas. 1604569113

Riehl, B. D., Park, J. H., Kwon, I. K., and Lim, J. Y. (2012). Mechanical stretching for tissue engineering: two-dimensional and three-dimensional constructs. Tissue Eng. Part B Rev. 18, 288-300. doi: 10.1089/ten.teb.2011.0465

Rinoldi, C., Costantini, M., Kijeñska-Gawroñska, E., Testa, S., Fornetti, E., Heljak, M., et al. (2019). Tendon tissue engineering: effects of mechanical and biochemical stimulation on stem cell alignment on cell-laden hydrogel yarns. Adv. Healthc. Mater. 8:1801218. doi: 10.1002/adhm.201801218

Rodriguez, M. L., Werner, T. R., Becker, B., Eschenhagen, T., and Hirt, M. N. (2019). A magnetics-based approach for fine-tuning afterload in engineered heart tissues. ACS Biomater. Sci. Eng. 13, 3-11. 
Roeder, B. A., Kokini, K., Sturgis, J. E., Robinson, J. P., and Voytik-Harbin, S. L. (2002). Tensile mechanical properties of three-dimensional type I collagen extracellular matrices with varied microstructure. J. Biomech. Eng. 124, 214222. doi: 10.1115/1.1449904

Ronaldson-Bouchard, K., Ma, S. P., Yeager, K., Chen, T., Song, L., Sirabella, D., et al. (2018). Advanced maturation of human cardiac tissue grown from pluripotent stem cells. Nature 556, 239-243. doi: 10.1038/s41586-018-0016-3

Sainz de Aja, J., and Kim, C. F. (2020). May the (mechanical) force be with AT2. Cell 180, 20-22. doi: 10.1016/j.cell.2019.12.020

Salameh, A., Karl, S., Djilali, H., Dhein, S., Janousek, J., and Daehnert, I. (2010). Opposing and synergistic effects of cyclic mechanical stretch and $\alpha$ - or $\beta$ adrenergic stimulation on the cardiac gap junction protein $\mathrm{Cx} 43$. Pharmacol. Res. 62, 506-513. doi: 10.1016/j.phrs.2010.08.002

Sarker, B., Bagchi, A., Walter, C., Almeida, J., and Pathak, A. (2019). Longer collagen fibers trigger multicellular streaming on soft substrates via enhanced forces and cell-cell cooperation. J. Cell Sci. 132, jcs.226753.

Scheiwe, A. C., Frank, S. C., Autenrieth, T. J., Bastmeyer, M., and Wegener, M. (2015). Subcellular stretch-induced cytoskeletal response of single fibroblasts within 3D designer scaffolds. Biomaterials 44, 186-194. doi: 10.1016/j. biomaterials.2014.12.018

Sheehy, S. P., Grosberg, A., and Parker, K. K. (2012). The contribution of cellular mechanotransduction to cardiomyocyte form and function. Biomech. Model. Mechanobiol. 11, 1227-1239. doi: 10.1007/s10237-012-0419-2

Sopher, R. S., Tokash, H., Natan, S., Sharabi, M., Shelah, O., Tchaicheeyan, O., et al. (2018). Nonlinear elasticity of the ECM fibers facilitates efficient intercellular communication. Biophys. J. 115, 1357-1370. doi: 10.1016/j.bpj.2018. 07.036

Stoppel, W. L., Kaplan, D. L., and Black, L. D. (2016). Electrical and mechanical stimulation of cardiac cells and tissue constructs. Adv. Drug Deliv. Rev. 96, 135-155. doi: 10.1016/j.addr.2015.07.009

Storm, C., Pastore, J. J., Mackintosh, F. C., Lubensky, T. C., and Janmey, P. A. (2005). Nonlinear elasticity in biological gels. Nature 435, 191-194. doi: 10 . 1038/nature 03521

Sun, J., Chen, J., Mohagheghian, E., and Wang, N. (2020). Force-induced gene up-regulation does not follow the weak power law but depends on H3K9 demethylation. Sci. Adv. 6:eaay9095. doi: 10.1126/sciadv.aay9095

Sun, J. Y., Zhao, X., Illeperuma, W. R. K., Chaudhuri, O., Oh, K. H., Mooney, D. J., et al. (2012). Highly stretchable and tough hydrogels. Nature 489, 133-136.

Svennersten, K., Berggren, M., Richter-Dahlfors, A., and Jager, E. W. H. (2011). Mechanical stimulation of epithelial cells using polypyrrole microactuators. $L a b$ Chip 11, 3287-3293. doi: 10.1039/c1lc20436j

Tajik, A., Zhang, Y., Wei, F., Sun, J., Jia, Q., Zhou, W., et al. (2016). Transcription upregulation via force-induced direct stretching of chromatin. Nat. Mater. 15, 1287-1296. doi: 10.1038/nmat4729

Tomei, A. A., Boschetti, F., Gervaso, F., and Swartz, M. A. (2009). 3D collagen cultures under well-defined dynamic strain: a novel strain device with a porous elastomeric support. Biotechnol. Bioeng. 103, 217-225. doi: 10.1002/bit.22236

Trepat, X., Deng, L., An, S. S., Navajas, D., Tschumperlin, D. J., Gerthoffer, W. T., et al. (2007). Universal physical responses to stretch in the living cell. Nature 447, 592-595. doi: 10.1038/nature05824

Vader, D., Kabla, A., Weitz, D., and Mahadevan, L. (2009). Strain-induced alignment in collagen gels. PLoS One 4:e5902. doi: 10.1371/journal.pone. 0005902

Van den Bulcke, A. I., Bogdanov, B., De Rooze, N., Schacht, E. H., Cornelissen, M., and Berghmans, H. (2000). Structural and rheological properties of methacrylamide modified gelatin hydrogels. Biomacromolecules 1, 31-38. doi: 10.1021/bm990017d

van Kelle, M. A. J., Khalil, N., Foolen, J., Loerakker, S., and Bouten, C. V. C. (2019). Increased cell traction-induced prestress in dynamically cultured microtissues. Front. Bioeng. Biotechnol. 7:41. doi: 10.3389/fbioe.2019. 00041

van Oosten, A. S. G., Chen, X., Chin, L., Cruz, K., Patteson, A. E., Pogoda, K., et al. (2019). Emergence of tissue-like mechanics from fibrous networks confined by close-packed cells. Nature 573, 96-101. doi: 10.1038/s41586-0191516-5

van Putten, S., Shafieyan, Y., and Hinz, B. (2015). Mechanical control of cardiac myofibroblasts. J. Mol. Cell Cardiol. 93, 133-142. doi: 10.1016/j.yjmcc.2015.11. 025
Vaughan, B. L., Galie, P. A., Stegemann, J. P., and Grotberg, J. B. (2013). A poroelastic model describing nutrient transport and cell stresses within a cyclically strained collagen hydrogel. Biophys. J. 105, 2188-2198. doi: 10.1016/ j.bpj.2013.08.048

Wakatsuki, T., Kolodney, M. S., Zahalak, G. I., and Elson, E. L. (2000). Cell mechanics studied by a reconstituted model tissue. Biophys. J. 79, 2353-2368. doi: 10.1016/s0006-3495(00)76481-2

Walker, M., Godin, M., and Pelling, A. E. (2018). A vacuum-actuated microtissue stretcher for long-term exposure to oscillatory strain within a $3 \mathrm{D}$ matrix. Biomed. Microdevices 20:43.

Walker, M., Godin, M., and Pelling, A. E. (2020). Mechanical stretch sustains myofibroblast phenotype and function in microtissues through latent TGF- $\beta 1$ activation. bioRxiv [Preprint] doi: 10.1101/2020.1101.1125.917179

Walker, M., Rizzuto, P., Godin, M., and Pelling, A. E. (2019). Structural and mechanical remodeling of the cytoskeleton studied in 3D microtissues under acute dynamic stretch. bioRxiv [Preprint] doi: 10.1101/780312

Wan, W., Cheng, B., Zhang, C., Ma, Y., Li, A., Xu, F., et al. (2019). Synergistic effect of matrix stiffness and inflammatory factors on osteogenic differentiation of human mesenchymal stem cells. Biophys. J. 117, 129-142. doi: 10.1016/j.bpj. 2019.05.019

Wang, E. Y., Rafatian, N., Zhao, Y., Lee, A., Lai, B. F. L., Lu, R. X., et al. (2019). Biowire model of interstitial and focal cardiac fibrosis. ACS Cent. Sci. 5, 1146-1158. doi: 10.1021/acscentsci.9b00052

Wang, M., Cheng, B., Yang, Y., Liu, H., Huang, G., Han, L., et al. (2019). Microchannel stiffness and confinement jointly induce the mesenchymalamoeboid transition of cancer cell migration. Nano Lett. 19, 5949-5958. doi: 10.1021/acs.nanolett.9b01597

Wang, W. Y., Davidson, C. D., Lin, D., and Baker, B. M. (2019). Actomyosin contractility-dependent matrix stretch and recoil induces rapid cell migration. Nat. Commun. 10:1186.

Wang, H., Abhilash, A. S., Chen, C. S., Wells, R. G., and Shenoy, V. B. (2014). Long-range force transmission in fibrous matrices enabled by tension-driven alignment of fibers. Biophys. J. 107, 2592-2603. doi: 10.1016/j.bpj.2014.09.044

Wang, L., Huang, G., Sha, B., Wang, S., Han, Y. L., Wu, J., et al. (2014). Engineering three-dimensional cardiac microtissues for potential drug screening applications. Curr. Med. Chem. 21, 2497-2509. doi: 10.2174/ 0929867321666131212152408

Wang, L., Li, Y., Chen, B., Liu, S., Li, M., Zheng, L., et al. (2015). Patterning cellular alignment through stretching hydrogels with programmable strain gradients. ACS Appl. Mater. Interfaces 7, 15088-15097. doi: 10.1021/acsami.5b04450

Watson, C. J., Phelan, D., Collier, P., Horgan, S., Glezeva, N., Cooke, G., et al. (2014). Extracellular matrix sub-types and mechanical stretch impact human cardiac fibroblast responses to transforming growth factor beta. Connect. Tissue Res. 55, 248-256. doi: 10.3109/03008207.2014.904856

Watson, S. A., Duff, J., Bardi, I., Zabielska, M., Atanur, S. S., Jabbour, R. J., et al. (2019). Biomimetic electromechanical stimulation to maintain adult myocardial slices in vitro. Nat. Commun. 10:2168.

Weinberger, F., Mannhardt, I., and Eschenhagen, T. (2017). Engineering cardiac muscle tissue: a maturating field of research. Circ. Res. 120, 1487-1500. doi: 10.1161/circresaha.117.310738

Wen, Q., and Janmey, P. A. (2013). Effects of non-linearity on cell-ECM interactions. Exp. Cell Res. 319, 2481-2489. doi: 10.1016/j.yexcr.2013.05.017

Wisdom, K. M., Adebowale, K., Chang, J., Lee, J. Y., Nam, S., Desai, R., et al. (2018). Matrix mechanical plasticity regulates cancer cell migration through confining microenvironments. Nat. Commun. 9:4144.

Wu, H., Yu, Y., Huang, H., Hu, Y., Fu, S., Wang, Z., et al. (2020). Progressive pulmonary fibrosis is caused by elevated mechanical tension on alveolar stem cells. Cell 180, 107-121.e17.

Xu, F., Zhao, R., Liu, A. S., Metz, T., Shi, Y., Bose, P., et al. (2015). A microfabricated magnetic actuation device for mechanical conditioning of arrays of $3 \mathrm{D}$ microtissues. Lab Chip 15, 2496-2503. doi: 10.1039/c4lc01395f

Xu, G.-K., Li, B., Feng, X.-Q., and Gao, H. (2016). A tensegrity model of cell reorientation on cyclically stretched substrates. Biophys. J. 111, 1478-1486. doi: 10.1016/j.bpj.2016.08.036

Yong, K. W., Li, Y. H., Huang, G. Y., Lu, T. J., Safwani, W. K. Z. W., PingguanMurphy, B., et al. (2015). Mechano-regulation of cardiac myofibroblast differentiation: implications for cardiac fibrosis and therapy. Am. J. Physiol. Heart Circ. Physiol. 309, H532-H542. 
Yuk, H., Varela, C. E., Nabzdyk, C. S., Mao, X., Padera, R. F., Roche, E. T., et al. (2019). Dry double-sided tape for adhesion of wet tissues and devices. Nature 575, 169-174. doi: 10.1038/s41586-019-1710-5

Yuk, H., Zhang, T., Lin, S., Parada, G. A., and Zhao, X. (2016). Tough bonding of hydrogels to diverse non-porous surfaces. Nat. Mater. 15, 190-196. doi: 10.1038/nmat4463

Yung, Y. C., Chae, J., Buehler, M. J., Hunter, C. P., and Mooney, D. J. (2009). Cyclic tensile strain triggers a sequence of autocrine and paracrine signaling to regulate angiogenic sprouting in human vascular cells. Proc. Natl. Acad. Sci. U.S.A. 106, 15279-15284. doi: 10.1073/pnas.0905891106

Zhang, X., Wang, W., Li, F., and Voiculescu, I. (2017). Stretchable impedance sensor for mammalian cell proliferation measurements. Lab Chip 17, 20542066. doi: 10.1039/c7lc00375g

Zhao, G., Bao, X., Huang, G., Xu, F., and Zhang, X. (2019). Differential effects of directional cyclic stretching on the functionalities of enginThe soft and hardheartedness of cardiac fibroblastseered cardiac tissues. ACS Appl. Bio Mater. 2, 3508-3519. doi: 10.1021/acsabm.9b00414

Zhao, Y., Rafatian, N., Feric, N. T., Cox, B. J., Aschar-Sobbi, R., Wang, E. Y., et al. (2019). A platform for generation of chamber-specific cardiac tissues and disease modeling. Cell 176, 913-927. doi: 10.1016/j.cell.2018. 11.042

Zhao, G., Zhang, X., Lu, T. J., and Xu, F. (2015). Recent advances in electrospun nanofibrous scaffolds for cardiac tissue engineering. Adv. Funct. Mater. 25, 5726-5738. doi: 10.1002/adfm.201502142

Zhao, R., Boudou, T., Wang, W.-G., Chen, C. S., and Reich, D. H. (2013). Decoupling cell and matrix mechanics in engineered microtissues using magnetically actuated microcantilevers. Adv. Mater. 25, 1699-1705. doi: 10 . 1002/adma.201203585

Zhao, R., Chen, C. S., and Reich, D. H. (2014). Force-driven evolution of mesoscale structure in engineered $3 \mathrm{D}$ microtissues and the modulation of tissue stiffening. Biomaterials 35, 5056-5064. doi: 10.1016/j.biomaterials.2014. 02.020
Zhong, Y., Kong, D., Dai, L., and Ji, B. (2011). Frequency-dependent focal adhesion instability and cell reorientation under cyclic substrate stretching. Cell. Mol. Bioeng. 4:442. doi: 10.1007/s12195-011-0187-6

Zhong, Z., Zeng, X.-L., Ni, J.-H., and Huang, X.-F. (2011). Comparison of the biological response of osteoblasts after tension and compression. Eur. J. Orthod. 35, 59-65. doi: 10.1093/ejo/cjr016

Zhu, L., Fan, X., Wang, B., Liu, L., Yan, X., Zhou, L., et al. (2017). Biomechanically primed liver microtumor array as a high-throughput mechanopharmacological screening platform for stroma-reprogrammed combinatorial therapy. Biomaterials 124, 12-24. doi: 10.1016/j.biomaterials.2017.01.030

Zimmermann, W. H., Fink, C., Kralisch, D., Remmers, U., Weil, J., and Eschenhagen, T. (2000). Three-dimensional engineered heart tissue from neonatal rat cardiac myocytes. Biotechnol. Bioeng. 68, 106-114. doi: 10.1002/ (sici)1097-0290(20000405)68:1<106::aid-bit13>3.0.co;2-3

Zimmermann, W. H., Melnychenko, I., Wasmeier, G., Didie, M., Naito, H., Nixdorff, U., et al. (2006). Engineered heart tissue grafts improve systolic and diastolic function in infarcted rat hearts. Nat. Med. 12, 452-458. doi: 10.1038/ nm1394

Zimmermann, W. H., Schneiderbanger, K., Schubert, P., Didie, M., Munzel, F., Heubach, J. F., et al. (2002). Tissue engineering of a differentiated cardiac muscle construct. Circ. Res. 90, 223-230. doi: 10.1161/hh0202.103644

Conflict of Interest: The authors declare that the research was conducted in the absence of any commercial or financial relationships that could be construed as a potential conflict of interest.

Copyright (c) 2020 Zhang, Huang and Xu. This is an open-access article distributed under the terms of the Creative Commons Attribution License (CC BY). The use, distribution or reproduction in other forums is permitted, provided the original author(s) and the copyright owner(s) are credited and that the original publication in this journal is cited, in accordance with accepted academic practice. No use, distribution or reproduction is permitted which does not comply with these terms. 